\title{
Wave Propagation in Nanodoped Films
}

\author{
Pierre Hillion*
}

Institut Henri Poincaré, 86 Bis Route de Croissy, 78110 Le Vésinet, France

\begin{abstract}
We analyze the propagation of electromagnetic plane waves through a dielectric film endo-wed with a nano doped permittivity made of a sequence of Dirac delta pulses.
\end{abstract}

Keywords: Nanodoping, Dielectric film, Dirac pulses, TE, TM fields

\section{INTRODUCTION}

The propagation of electromagnetic plane waves through homogeneous and periodically stratified films has been the subject of several important works since the first edition of the Born-Wolf book [1] and after Arzéliès' publications [2]. We are interested here in the beha-viour of TE, TM harmonic plane waves incident on the $\mathrm{z}=0$ face of a dielectric film $0 \leq \mathrm{z} \leq \mathrm{d}$ with a nano doped permittivity, the nanodoping being obtained from a sequence of delta Dirac pulses. We also consider succinctly magnetic composite films nanodoped with magnetic hol-low nanospheres.With the light velocity $\mathrm{c}=1$, the permeability $\mu=1$, the permittivity $\varepsilon_{1}, \mathrm{n}_{1}$ $=\sqrt{ } \varepsilon_{1}$ and $\exp (-\mathrm{i} \omega \mathrm{t})$ implicit, the components $\mathrm{E}_{\mathrm{y}}, \mathrm{H}_{\mathrm{x}}, \mathrm{H}_{\mathrm{z}}$ of the incident TE wave are [1] in $\mathrm{z} \leq 0$

$\mathrm{E}_{\mathrm{y}}^{\mathrm{i}}=\mathrm{A}_{\mathrm{e}} \psi_{\mathrm{i}}(\mathrm{x}, \mathrm{z}), \mathrm{H}_{\mathrm{x}}^{\mathrm{i}}=-\mathrm{A}_{\mathrm{e}} \mathrm{n}_{1} \cos \theta_{\mathrm{i}} \psi_{\mathrm{i}}(\mathrm{x}, \mathrm{z})$,

$\mathrm{H}_{\mathrm{z}}{ }^{\mathrm{i}}=\mathrm{A}_{\mathrm{e}} \mathrm{n}_{1} \sin \theta_{\mathrm{i}} \psi_{\mathrm{i}}(\mathrm{x}, \mathrm{z})$

$\psi_{\mathrm{i}}(\mathrm{x}, \mathrm{z})=\exp \left[\mathrm{i} \omega \mathrm{n}_{1}\left(\mathrm{x} \sin \theta_{\mathrm{i}}+\mathrm{z} \cos \theta_{\mathrm{i}}\right)\right]$

while, since $\theta_{\mathrm{r}}=\pi-\theta_{\mathrm{i}}$, the reflected field is

$\mathrm{E}_{\mathrm{y}}{ }^{\mathrm{r}}=\mathrm{R}_{\mathrm{e}} \psi_{\mathrm{r}}(\mathrm{x}, \mathrm{z}), \mathrm{H}_{\mathrm{x}}{ }^{\mathrm{r}}=\mathrm{R}_{\mathrm{e}} \mathrm{n}_{1} \cos \theta_{\mathrm{i}} \psi_{\mathrm{r}}(\mathrm{x}, \mathrm{z})$,

$\mathrm{H}_{\mathrm{z}}{ }^{\mathrm{r}}=\mathrm{R}_{\mathrm{e}} \mathrm{n}_{1} \sin \theta_{\mathrm{i}} \psi_{\mathrm{r}}(\mathrm{x}, \mathrm{z})$

$\psi_{\mathrm{r}}(\mathrm{x}, \mathrm{z})=\exp \left[\mathrm{i} \omega \mathrm{n}_{1}\left(\mathrm{x} \sin \theta_{\mathrm{i}}-\mathrm{z} \cos \theta_{\mathrm{i}}\right)\right]$

$A_{e}, R_{e}$ are the field amplitudes and we have similarly for the TM field with components $\mathrm{H}_{\mathrm{y}}, \mathrm{E}_{\mathrm{x}}, \mathrm{E}_{\mathrm{z}}$

$\mathrm{H}_{\mathrm{y}}{ }^{\mathrm{i}}=-\mathrm{A}_{\mathrm{m}} \mathrm{n}_{1} \psi_{\mathrm{i}}(\mathrm{x}, \mathrm{z}), \mathrm{E}_{\mathrm{x}}{ }^{\mathrm{i}}=-\mathrm{A}_{\mathrm{m}} \cos \theta_{\mathrm{i}} \psi_{\mathrm{i}}(\mathrm{x}, \mathrm{z})$,

$\mathrm{E}_{\mathrm{z}}^{\mathrm{i}}=\mathrm{A}_{\mathrm{m}} \sin \theta_{\mathrm{i}} \psi_{\mathrm{i}}(\mathrm{x}, \mathrm{z})$

$\mathrm{H}_{\mathrm{y}}{ }^{\mathrm{r}}=-\mathrm{R}_{\mathrm{m}} \mathrm{n}_{1} \psi_{\mathrm{r}}(\mathrm{x}, \mathrm{z}), \mathrm{E}_{\mathrm{x}}{ }^{\mathrm{r}}=\mathrm{A}_{\mathrm{m}} \cos \theta_{\mathrm{i}} \psi_{\mathrm{r}}(\mathrm{x}, \mathrm{z})$,

$\mathrm{E}_{\mathrm{z}}{ }^{\mathrm{r}}=\mathrm{R}_{\mathrm{m}} \sin \theta_{\mathrm{i}} \psi_{\mathrm{r}}(\mathrm{x}, \mathrm{z})$

with the expressions (1a), (2a) of $\psi_{\mathrm{i}}, \psi_{\mathrm{r}}$.

\section{TE, TM FIELDS INSIDE A FILM WITH NANODOPED PERMITTIVITY}

We consider a dielectric film with permittivity nano doped according to the relation

*Address correspondence to this author at the Institut Henri Poincaré, 86 Bis Route de Croissy, 78110 Le Vésinet, France; Tel: 33139766401 ;

E-mail: pierre.hillion@wanadoo.fr $\varepsilon(\mathrm{z})=\varepsilon_{0}+\eta \Sigma_{\mathrm{m}=1}{ }^{\mathrm{M}} \delta\left(\mathrm{z} / \mathrm{z}_{0}-\mathrm{m}\right), 0 \leq \mathrm{z} \leq \mathrm{d}, \mathrm{Mz}_{0} \leq \mathrm{d}$

$=\varepsilon_{0}+\eta \mathrm{z}_{0} \Sigma_{\mathrm{m}=1}^{\mathrm{M}} \delta\left(\mathrm{z}-\mathrm{mz}_{0}\right)$

$\varepsilon_{0}, \eta, z_{0}>0$ are constant parameters and $\delta$ the Dirac distribution.This permittivity has the property to have a first derivative null, the relation $\mathrm{f}(\mathrm{x}) \delta^{\prime}(\mathrm{x})=-\mathrm{f}^{\prime}(\mathrm{x}) \delta(\mathrm{x})$ implying $\varepsilon^{\prime}(\mathrm{z})=0$

since $\eta \mathrm{z}_{0}$ is constant.

Now, inside the film, the Maxwell equations are with $\mu=\mathrm{c}=$ 1 and $\exp (-\mathrm{i} \omega \mathrm{t})$ implicit

$\partial_{\mathrm{y}} \mathrm{H}_{\mathrm{z}}^{\dagger}-\partial_{\mathrm{z}} \mathrm{H}_{\mathrm{y}}^{\dagger}+\mathrm{i} \omega \varepsilon(\mathrm{z}) \mathrm{E}_{\mathrm{x}}^{\dagger}=0, \partial_{\mathrm{y}} \mathrm{E}_{\mathrm{z}}^{\dagger}-\partial_{\mathrm{z}} \mathrm{E}_{\mathrm{y}}^{\dagger}-\mathrm{i} \omega \mathrm{H}_{\mathrm{x}}^{\dagger}=0$

$\partial_{\mathrm{z}} \mathrm{H}_{\mathrm{x}}^{\dagger}-\partial_{\mathrm{x}} \mathrm{H}_{\mathrm{z}}^{\dagger}+\mathrm{i} \omega \varepsilon(\mathrm{z}) \mathrm{E}_{\mathrm{y}}^{\dagger}=0, \partial_{\mathrm{z}} \mathrm{E}_{\mathrm{x}}^{\dagger}-\partial_{\mathrm{x}} \mathrm{E}_{\mathrm{z}}^{\dagger}-\mathrm{i} \omega \mathrm{H}_{\mathrm{y}}^{\dagger}=0$

$\partial_{\mathrm{x}} \mathrm{H}_{\mathrm{y}}^{\dagger}-\partial_{\mathrm{y}} \mathrm{H}_{\mathrm{x}}^{\dagger}+\mathrm{i} \omega \varepsilon(\mathrm{z}) \mathrm{E}_{\mathrm{z}}^{\dagger}=0, \partial_{\mathrm{x}} \mathrm{E}_{\mathrm{y}}^{\dagger}-\partial_{\mathrm{y}} \mathrm{E}_{\mathrm{x}}^{\dagger}-\mathrm{i} \omega \mathrm{H}_{\mathrm{z}}^{\dagger}=0(6,7)$

For the TE field, depending only on $\mathrm{x}, \mathrm{z}$, the equations (6, 7) reduce to

$\partial_{\mathrm{z}} \mathrm{E}_{\mathrm{y}}^{\dagger}=-\mathrm{i} \omega \mathrm{H}_{\mathrm{x}}^{\dagger}, \partial_{\mathrm{x}} \mathrm{E}_{\mathrm{y}}^{\dagger}=\mathrm{i} \omega \mathrm{H}_{\mathrm{z}}^{\dagger}$,

$\partial_{z} H_{x}^{\dagger}-\partial_{x} H_{z}^{\dagger}+i \omega \varepsilon(z) E_{y}^{\dagger}=0$

and for the TM field

$\partial_{\mathrm{z}} \mathrm{H}_{\mathrm{y}}^{\dagger}=\mathrm{i} \omega \varepsilon(\mathrm{z}) \mathrm{E}_{\mathrm{x}}^{\dagger}, \partial_{\mathrm{x}} \mathrm{H}_{\mathrm{y}}^{\dagger}=-\mathrm{i} \omega \varepsilon(\mathrm{z}) \mathrm{E}_{\mathrm{z}}^{\dagger}$,

$\partial_{\mathrm{z}} \mathrm{E}_{\mathrm{x}}^{\dagger}-\partial_{\mathrm{x}} \mathrm{E}_{\mathrm{z}}^{\dagger}-\mathrm{i} \omega \mathrm{H}_{\mathrm{y}}^{\dagger}=0$

These fields are consistent with (1-4), just changing $\varepsilon(z)$ into $\varepsilon_{1}$ and using (1a), (2a).

Eliminating $\mathrm{H}_{\mathrm{x}}^{\dagger}, \mathrm{H}_{\mathrm{z}}^{\dagger}$ from (8a) and taking into account $\varepsilon^{\prime}(\mathrm{z})=0$ gives for $\mathrm{E}_{\mathrm{y}}^{\dagger}$ the same wave equation as that obtained for $\mathrm{H}_{\mathrm{y}}{ }^{\dagger}$ by eliminating $\mathrm{E}_{\mathrm{x}}{ }^{\dagger}, \mathrm{E}_{\mathrm{z}}{ }^{\dagger}$ from (8b)

$\left[\partial_{\mathrm{x}}{ }^{2}+\partial_{\mathrm{z}}{ }^{2}+\omega^{2} \mathrm{n}^{2}(\mathrm{z})\right]\left\{\mathrm{E}_{\mathrm{y}}^{\dagger}, \mathrm{H}_{\mathrm{y}}^{\dagger}\right\}=0, \mathrm{n}^{2}(\mathrm{z})=\varepsilon(\mathrm{z})$

We look for the solutions of Eq.(9) in the form

$\mathrm{E}_{\mathrm{y}}^{\dagger}(\mathrm{x}, \mathrm{z})=\mathrm{T}_{\mathrm{e}} \exp \left(\mathrm{i}^{\mathrm{a}} \mathrm{n}_{0} \mathrm{x} \sin \theta^{\dagger}\right) \phi(\mathrm{z})$

$\left.\mathrm{H}_{\mathrm{y}}^{\dagger}(\mathrm{x}, \mathrm{z})=-\mathrm{n}_{0} \mathrm{~T}_{\mathrm{m}} \exp \left(\mathrm{i} \omega \mathrm{n}_{0} \mathrm{x} \sin \theta^{\dagger}\right) \phi(\mathrm{z}) \mathrm{b}\right)$

$\mathrm{n}_{0}=\sqrt{ } \varepsilon_{0}$ and $\mathrm{T}_{\mathrm{e}}, \mathrm{T}_{\mathrm{m}}$ are the field amplitudes. Substituting (10) into (9) gives the differential equation satisfied by $\phi(z)$

$\partial_{z}^{2} \phi(z)+\omega^{2}\left[n^{2}(z)-n_{0}^{2} \sin ^{2} \theta^{\dagger}\right] \phi(z)=0$

The solutions of (11) are discusssed in Appendix A and assuming $\eta \ll<1$ we get to the $0\left(\eta^{2}\right)$ order 
$\phi(\mathrm{z})=\phi_{0}(\mathrm{z})+\eta \sum_{\mathrm{m}=1}^{\mathrm{M}} \phi_{\mathrm{m}}(\mathrm{z})+0\left(\eta^{2}\right)$

with

$\phi_{0}(\mathrm{z})=\exp \left(\mathrm{in}_{0} \cos \theta^{\dagger} \omega \mathrm{z}\right)$

and

$\phi_{\mathrm{m}}(\mathrm{z})=\left(\mathrm{i} \omega \mathrm{z}_{0} / 2 \pi \mathrm{n}_{0} \cos \theta^{\dagger}\right) \exp \left[\mathrm{i} \omega \mathrm{n}_{0} \cos \theta^{\dagger}\right.$

$\left.\left\{\mathrm{mz}_{0}+\left|\mathrm{z}-\mathrm{mz}_{0}\right|\right\}\right]$

Now, in the dielectric film, the field reflected on the $\mathrm{z}=\mathrm{d}$ face has to be taken into account so that according to (10) the components $\mathrm{E}_{\mathrm{y}}^{\dagger}(\mathrm{x}, \mathrm{z}), \mathrm{H}_{\mathrm{y}}^{\dagger}(\mathrm{x}, \mathrm{z})$ are

$\mathrm{E}_{\mathrm{y}}^{\dagger}(\mathrm{x}, \mathrm{z})=\beta^{\dagger}(\mathrm{x})\left[\mathrm{T}_{\mathrm{e}}{ }^{1} \phi(\mathrm{z})+\mathrm{T}_{\mathrm{e}}{ }^{2} \phi(\{\mathrm{d}-\mathrm{z}\})\right]$

$\mathrm{H}_{\mathrm{y}}^{\dagger}(\mathrm{x}, \mathrm{z})=-\mathrm{n}_{0} \beta^{\dagger}(\mathrm{x})\left[\mathrm{T}_{\mathrm{m}}{ }^{1} \phi(\mathrm{z})+\mathrm{T}_{\mathrm{m}}{ }^{2} \phi(\{\mathrm{d}-\mathrm{z}\})\right]$

in which

$\beta^{\dagger}(\mathrm{x})=\exp \left(\mathrm{i} \omega \mathrm{n}_{0} \mathrm{x} \sin \theta^{\dagger}\right)$

Substituting (13a) into (8a) gives

$\mathrm{H}_{\mathrm{x}}^{\dagger}(\mathrm{x}, \mathrm{z})=\mathrm{i} \omega \beta^{\dagger}(\mathrm{x})\left[\mathrm{T}_{\mathrm{e}}{ }^{1} \phi^{\prime}(\mathrm{z})+\mathrm{T}_{\mathrm{e}}{ }^{2} \phi^{\prime}(\{\mathrm{d}-\mathrm{z}\})\right]$

$\mathrm{H}_{\mathrm{z}}^{\dagger}(\mathrm{x}, \mathrm{z})=\mathrm{n}_{0} \sin \theta^{\dagger} \beta^{\dagger}(\mathrm{x})\left[\mathrm{T}_{\mathrm{e}}{ }^{1} \phi(\mathrm{z})+\mathrm{T}_{\mathrm{e}}{ }^{2} \phi(\{\mathrm{d}-\mathrm{z}\})\right]$

Similarly with (13b) substituted into (8b)

$\mathrm{E}_{\mathrm{x}}{ }^{\dagger}(\mathrm{x}, \mathrm{z})=\left[\mathrm{in}_{0} / \varepsilon(\mathrm{z})\right] \beta^{\dagger}(\mathrm{x})\left[\mathrm{T}_{\mathrm{m}}{ }^{1} \phi^{\prime}(\mathrm{z})+\right.$

$\left.\mathrm{T}_{\mathrm{m}}^{2} \phi^{\prime}(\{\mathrm{d}-\mathrm{z}\})\right]$

$\mathrm{E}_{\mathrm{z}}^{\dagger}(\mathrm{x}, \mathrm{z})=\left[\mathrm{n}_{0}{ }^{2} / \varepsilon(\mathrm{z})\right] \sin \theta^{\dagger} \beta^{\dagger}(\mathrm{x})$

$\left[\mathrm{T}_{\mathrm{m}}{ }^{1} \phi(\mathrm{z})+\mathrm{T}_{\mathrm{m}}{ }^{2} \phi(\{\mathrm{d}-\mathrm{z}\})\right]$

We now have all the ingredients to analyze the electromagnetic plane wave propagation through the nano doped dielectric film.

\section{ELECTROMAGNETIC WAVE PROPAGATION}

\subsection{TE Field}

The amplitudes of the TE field must satisfy boundary conditions at $\mathrm{z}=0$ and $\mathrm{z}=\mathrm{d}$. Then, noting first that the Descartes-Snell relation $n_{1} \sin \theta_{i}=n_{0} \sin \theta^{\dagger}$ transforms (14) into

$\beta^{\dagger}(\mathrm{x})=\exp \left(\mathrm{i} \omega \mathrm{n}_{1} \mathrm{x} \sin \theta_{\mathrm{i}}\right)$

we have at $\mathrm{z}=0$

$\mathrm{E}_{\mathrm{y}}^{\mathrm{i}}(\mathrm{x}, 0)+\mathrm{E}_{\mathrm{y}}^{\mathrm{r}}(\mathrm{x}, 0)=\mathrm{E}_{\mathrm{y}}{ }^{\dagger}(\mathrm{x}, 0)$,

$\mathrm{H}_{\mathrm{x}}{ }^{\mathrm{i}}(\mathrm{x}, 0)+\mathrm{H}_{\mathrm{x}}{ }^{\mathrm{r}}(\mathrm{x}, 0)=\mathrm{H}_{\mathrm{x}}{ }^{\dagger}(\mathrm{x}, 0)$

and, taking into account (1), (1a), (2), (2a) and (13a), (15a) together with (17), we get from (18)

$\mathrm{R}_{\mathrm{e}}+\mathrm{A}_{\mathrm{e}}=\mathrm{T}_{\mathrm{e}}^{1} \phi(0)+\mathrm{T}_{\mathrm{e}}^{2} \phi(\mathrm{d})$

$\mathrm{n}_{1} \cos \theta_{\mathrm{i}}\left(\mathrm{R}_{\mathrm{e}}-\mathrm{A}_{\mathrm{e}}\right)=\mathrm{i}\left[\mathrm{T}_{\mathrm{e}}^{1} \phi^{\prime}(0)+\mathrm{T}_{\mathrm{e}}^{2} \phi^{\prime}(\mathrm{d})\right]$

Now, to get the TE field $\mathrm{E}_{\mathrm{y}}{ }^{\mathrm{t}}, \mathrm{H}_{\mathrm{x}}{ }^{\mathrm{t}}, \mathrm{H}_{\mathrm{z}}{ }^{\mathrm{t}}$ outside the film for $\mathrm{z}$ $>\mathrm{d}$, one has just to change in (1) the amplitude $\mathrm{A}_{\mathrm{e}}$ into $\mathrm{A}_{\mathrm{t}, \mathrm{e}}$ so that the boundary conditions at $\mathrm{z}=\mathrm{d}$ are

$\mathrm{E}_{\mathrm{y}}{ }^{\mathrm{t}}(\mathrm{x}, \mathrm{d})=\mathrm{E}_{\mathrm{y}}{ }^{\dagger}(\mathrm{x}, \mathrm{d}), \mathrm{H}_{\mathrm{x}}^{\mathrm{t}}(\mathrm{x}, \mathrm{d})=\mathrm{H}_{\mathrm{x}}{ }^{\dagger}(\mathrm{x}, \mathrm{d})$

and, still using (1), (1a) and (13a), (15a), (17), we get

$\mathrm{T}_{\mathrm{e}}^{1} \phi(\mathrm{d})+\mathrm{T}_{\mathrm{e}}^{2} \phi(0)=\gamma \mathrm{A}_{\mathrm{t}, \mathrm{e}}$

$\mathrm{i}\left[\mathrm{T}_{\mathrm{e}}^{1} \phi^{\prime}(\omega)+\mathrm{T}_{\mathrm{e}}^{2} \phi^{\prime}(0)\right]=-\mathrm{n}_{1} \cos \theta_{\mathrm{i}} \gamma \mathrm{A}_{\mathrm{t}, \mathrm{e}}$ in which

$\gamma=\exp \left(\mathrm{i} \omega \mathrm{n}_{1} \mathrm{~d} \sin \theta_{\mathrm{i}}\right)$

So, we get from (19) and (21) four relations to determine the four unknown amplitudes $\mathrm{R}_{\mathrm{e}}, \mathrm{T}_{\mathrm{e}}{ }^{1} \mathrm{~T}_{\mathrm{e}}{ }^{2}, \mathrm{~A}_{\mathrm{t}, \mathrm{e}}$, this set of equations is solved in Appendix B.

\subsection{TM Field}

The boundary conditions for the TM field are at $\mathrm{z}=0$ $\mathrm{H}_{\mathrm{y}}^{\mathrm{i}}(\mathrm{x}, 0)+\mathrm{H}_{\mathrm{y}}^{\mathrm{r}}(\mathrm{x}, 0)=\mathrm{H}_{\mathrm{y}}^{\dagger}(\mathrm{x}, 0)$,

$\mathrm{E}_{\mathrm{x}}^{\mathrm{i}}(\mathrm{x}, 0)+\mathrm{E}_{\mathrm{x}}^{\mathrm{r}}(\mathrm{x}, 0)=\mathrm{E}_{\mathrm{x}}^{\dagger}(\mathrm{x}, 0)$

Then, using (3), (4) with (1a), (2a) together with (13b), (16a), taking into account (17), we get since $\varepsilon(0)=\varepsilon_{0}=n_{0}^{2}$

$\mathrm{n}_{1}\left(\mathrm{R}_{\mathrm{m}}+\mathrm{A}_{\mathrm{m}}\right)=\mathrm{n}_{0}\left[\mathrm{~T}_{\mathrm{m}}{ }^{1} \phi(0)+\mathrm{T}_{\mathrm{m}}{ }^{2} \phi(\mathrm{d})\right]$

$\mathrm{n}_{0} \cos \theta_{\mathrm{i}}\left(\mathrm{R}_{\mathrm{m}}-\mathrm{A}_{\mathrm{m}}\right)=\mathrm{i}\left[\mathrm{T}_{\mathrm{m}}{ }^{1} \phi^{\prime}(0)+\mathrm{T}_{\mathrm{m}}{ }^{2} \phi^{\prime}(\mathrm{d})\right]$

Now the TM field in $\mathrm{z}>d$ has the expression (3) with $A_{m}$ changed into $A_{t, m}$ so that the boun-dary conditions at $\mathrm{z}=\mathrm{d}$ are

$\mathrm{H}_{\mathrm{y}}^{\mathrm{t}}(\mathrm{x}, \mathrm{d})=\mathrm{H}_{\mathrm{y}}^{\dagger}(\mathrm{x}, \mathrm{d}), \mathrm{E}_{\mathrm{x}}^{\mathrm{t}}(\mathrm{x}, \mathrm{d})=\mathrm{E}_{\mathrm{x}}^{\dagger}(\mathrm{x}, \mathrm{d})$

implying with $\gamma$ given by (21a) since $\varepsilon(d)=\varepsilon_{0}=n_{0}^{2}$

$\mathrm{n}_{0}\left[\mathrm{~T}_{\mathrm{m}}{ }^{1} \phi(\mathrm{d})+\mathrm{T}_{\mathrm{m}}{ }^{2} \phi(0)\right]=\gamma \mathrm{n}_{1} \mathrm{~A}_{\mathrm{t}, \mathrm{m}}$

$\mathrm{i}\left[\mathrm{T}_{\mathrm{m}}{ }^{1} \phi^{\prime}(\mathrm{d})+\mathrm{T}_{\mathrm{m}}{ }^{2} \phi^{\prime}(0)\right]=-\gamma \mathrm{n}_{0} \cos \theta_{\mathrm{i}} \mathrm{A}_{\mathrm{t}, \mathrm{m}}$

We get from (23), (25) four relations to determine $R_{m}$, $, \mathrm{T}_{\mathrm{m}},{ }^{1}, \mathrm{~T}_{\mathrm{m}},{ }^{2}, \mathrm{~A}_{\mathrm{t}, \mathrm{m}}$ which is made in Ap-pendix $\mathrm{B}$

\section{DISCUSSION}

High-k dielectrics are used for instance in semiconductor manufacturing process to replace silicon gate dielectrics, allowing a miniutarization of microelectronics component with better performances in thin materials such as dielectric films. Nano doped dielectrics offer the possibility of high-k dielectrics. Here for instance, the mean value of the dielectric constant is

$\varepsilon=1 / \mathrm{d} \int_{0}^{\mathrm{d}} \varepsilon(\mathrm{z}) \mathrm{dz}$

that is substituting (5) into (26)

$\varepsilon=\varepsilon_{0}+\eta / \omega \mathrm{d} \int_{-\infty}^{\infty}[\mathrm{U}(\mathrm{z})-\mathrm{U}(\mathrm{z}-\mathrm{d})] \sum_{\mathrm{m}}{ }^{\mathrm{M}} \delta\left(\mathrm{z}-\mathrm{mz}_{0}\right)$

$=\varepsilon_{0}+\eta / \omega \mathrm{d} \sum_{\mathrm{m}}{ }^{\mathrm{M}}\left[\mathrm{U}\left(\mathrm{mz}_{0}\right)-\mathrm{U}\left(\mathrm{mz}_{0}-\mathrm{d}\right)\right]$

$=\varepsilon_{0}+\mathrm{M \eta} / \omega \mathrm{d}$

taking great values when $\mathrm{M} / \omega$ is high.

Incidently, the sum in (5) is the truncated series of the Dirac distribution $[4,5]$

$\pi \delta\left[\sin \left(\pi \mathrm{z} / \mathrm{z}_{0}\right)\right]=\sum_{\mathrm{n}} \delta\left(\mathrm{z} / \mathrm{z}_{0}-\mathrm{n}\right), \mathrm{n}$ integer in $(-\infty, \infty)$

The matrix technique $[1,2]$ used to analyze the propagation of electromagnetic plane waves through homogeneous and periodically stratified dielectric films is not suitable for TE, TM fields inside a film with the permittivity (5) which is neither homogeneous nor stratified be-cause the dielectric constant is only perturbed by the Dirac pulses at local points. The impor-tance of $\varepsilon^{\prime}(\mathrm{z})=0$, to get the wave equation (9) must be stressed. 
We have obtained in Appendix A an $0\left(\eta^{2}\right)$ approximation of TE, TM fields in which the Green's function of the 1DHelmholtz equation intervenes rather naturally. The object of this approximation was only to get a perception of the TE, TM behaviour, but it is clear that an important numerical analysis has to be performed when $\eta$ is not very small.

Finally, it has ben assumed that 1D-nano doping may be described by a sequence of delta Dirac pulses, the nano dots being assimilated to points. This postulat could be generalized to 2D and 3D nano doping from the relations [5]

$\delta(\mathrm{r}) / \pi \mathrm{r}=\delta(\mathrm{x}) \delta(\mathrm{y}) \mathrm{r}=\left(\mathrm{x}^{2}+\mathrm{y}^{2}\right)^{1 / 2}$

$\delta(\mathrm{r}) / 2 \pi \mathrm{r}^{2}=\delta(\mathrm{x}) \delta(\mathrm{y}) \delta(\mathrm{z}) \mathrm{r}=\left(\mathrm{x}^{2}+\mathrm{y}^{2}+\mathrm{z}^{2}\right)^{1 / 2}$

The following generalization of (5) could be used to describe nanodoped photonic crystals made of multilayer films [6]

$\varepsilon_{\mathrm{j}}(\mathrm{z})==\varepsilon_{0}+\mathrm{z}_{0} \Sigma_{\mathrm{m}=1}{ }^{\mathrm{M}} \eta_{\mathrm{j}} \delta\left(\mathrm{z}-\mathrm{mz}_{0}\right), \mathrm{j}=1,2 \ldots . \ddot{\mathrm{I}}$

in which $\mathrm{j}$ is the number of layers.

\section{MAGNETIC NANO COMPOSITE FILMS}

Magnetic nano composite films are used specially to enhance the film coercivity [7-11]. that is their resistance to becoming demagnetized. The non existence of magnetic monopoles prevents to imagine the doping of these films as made of nano dots and, we have instead to consider magnetic hollow nano spheres [12-17]. Then, the permeability $\mu(\mathrm{z})$ in $0 \leq \mathrm{z} \leq \mathrm{d}$ may be represented by the expansion

$\mu(\mathrm{z})=\mu_{0}+\sum_{\mathrm{m}=1}{ }^{\mathrm{M}} v\left(\mathrm{mz}_{0}\right) \delta\left(\mathrm{z}-\mathrm{mz}_{0}\right)$

$\mathrm{mz}_{0}$ is the center of a hollow nano sphere and $v\left(\mathrm{mz}_{0}\right)$ depends on its nature and on its radius $[14,15]$. This permittivity satisfies also the condittion $\mu^{\prime}(\mathrm{z})=0$.

Proceeding as in (26a), we get from (30) for the mean value permittivity $\mu$ of this magnetic nano composite film giving the possibility to check its coercivity performance.

$\mu=\mu_{0}+1 / \omega \mathrm{d} \sum_{\mathrm{m}}{ }^{\mathrm{M}} \mathrm{v}\left(\mathrm{mz}_{0}\right)$

Then, using (30) and assuming $\varepsilon=1$, it is easily checked that the equations $(8 \mathrm{a}, \mathrm{b})$ for TE,TM fields transform into

$\partial_{\mathrm{z}} \mathrm{E}_{\mathrm{y}}^{\dagger}=-\mathrm{i} \omega \mu(\mathrm{z}) \mathrm{H}_{\mathrm{x}}^{\dagger}, \partial_{\mathrm{x}} \mathrm{E}_{\mathrm{y}}^{\dagger}=\mathrm{i} \omega \mu(\mathrm{z}) \mathrm{H}_{\mathrm{z}}^{\dagger}$,

$\partial_{\mathrm{z}} \mathrm{H}_{\mathrm{x}}^{\dagger}-\partial_{\mathrm{x}} \mathrm{H}_{\mathrm{z}}^{\dagger}+\mathrm{i} \omega \mathrm{E}_{\mathrm{y}}^{\dagger}=0$

$\partial_{\mathrm{z}} \mathrm{H}_{\mathrm{y}}^{\dagger}=\mathrm{i} \omega \mathrm{E}_{\mathrm{x}}^{\dagger}, \partial_{\mathrm{x}} \mathrm{H}_{\mathrm{y}}^{\dagger}=-\mathrm{i} \omega \mathrm{E}_{\mathrm{z}}^{\dagger}$,

$\partial_{z} E_{x}^{\dagger}-\partial_{x} E_{z}^{\dagger}-i \omega \mu(z) H_{y}^{\dagger}=0$

so that since $\mu^{\prime}(\mathrm{z})=0$, the components $\mathrm{E}_{\mathrm{y}}{ }^{\dagger}, \mathrm{H}_{\mathrm{y}}{ }^{\dagger}$ are still solutions of the wave equation (9) in which now $\mathrm{n}^{2}(\mathrm{z})=\mu(\mathrm{z})$ and they take the form (13) with $\phi(z)$ satisfying the differential equation (12). Substituting (13) into (31a,b) gives the other two components of the TE, TM fields with according to $(31 \mathrm{a})$

$\left.\mathrm{H}_{\mathrm{x}}{ }^{\dagger}(\mathrm{x}, \mathrm{z})=[\mathrm{i} / \mu(\mathrm{z})] \beta^{\dagger}(\mathrm{x})\left[\mathrm{T}_{\mathrm{e}}{ }^{1} \phi^{\prime}(\mathrm{z})+\mathrm{T}_{\mathrm{e}}{ }^{2} \phi^{\prime}(\{\mathrm{d}-\mathrm{z}\})\right] \quad \mathrm{a}\right)$

$\mathrm{H}_{\mathrm{z}}^{\dagger}(\mathrm{x}, \mathrm{z})=\left[\mathrm{n}_{0} / \mu(\mathrm{z})\right] \sin \theta^{\dagger} \beta^{\dagger}(\mathrm{x})$

$\left[\mathrm{T}_{\mathrm{e}}^{1} \phi(\mathrm{z})+\mathrm{T}_{\mathrm{e}}^{2} \phi(\{\mathrm{d}-\mathrm{z}\})\right]$

and from $(31 b)$

$\mathrm{E}_{\mathrm{x}}^{\dagger}(\mathrm{x}, \mathrm{z})=\mathrm{in}_{0} \beta^{\dagger}(\mathrm{x})\left[\mathrm{T}_{\mathrm{m}}{ }^{1} \phi^{\prime}(\mathrm{z})+\mathrm{T}_{\mathrm{m}}{ }^{2} \phi^{\prime}(\{\mathrm{d}-\mathrm{z}\})\right]$
$\mathrm{E}_{\mathrm{z}}^{\dagger}(\mathrm{x}, \mathrm{z})=\mathrm{n}_{0}{ }^{2} \sin \theta^{\dagger} \beta^{\dagger}(\mathrm{x})\left[\mathrm{T}_{\mathrm{m}}{ }^{1} \phi(\mathrm{z})+\mathrm{T}_{\mathrm{m}}{ }^{2} \phi(\{\mathrm{d}-\mathrm{z}\})\right]$

From there, we may proceed as in Sec.3, using the boundary conditions at $\mathrm{z}=0$ and $\mathrm{z}=\mathrm{d}$ to get four equations to determine the four unknown amplitudes.

As previously stated, $\phi(\mathrm{z})$ is solution of Eq.(11) with $\mathrm{n}^{2}(\mathrm{z})=\mu(\mathrm{z})$. Let $v=\operatorname{Max}_{\mathrm{m}} v\left(\mathrm{mz}_{0}\right)$ then assuming $v<<1$ and consequently $v\left(\mathrm{mz}_{0}\right)<<1$ we have to the $0\left(v^{2}\right)$ order

$\phi(\mathrm{z})=\phi_{0}(\mathrm{z})+v \sum_{\mathrm{m}=1}^{\mathrm{M}} \phi_{\mathrm{m}}(\mathrm{z})+0\left(v^{2}\right)$

with $\phi_{0}(\mathrm{z}), \phi_{\mathrm{m}}(\mathrm{z})$ given by $(12 \mathrm{a}, \mathrm{b})$.

This analysis of magnetic nano composite films reposes on magnetic hollow nano sphere whose existence requires further works.

\section{APPENDIX A}

We discuss here the solutions of Eq.(11) rewritten for convenience

$\partial_{z}^{2} \phi(z)+\omega^{2}\left[n^{2}(z)-n_{0}^{2} \sin ^{2} \theta^{\dagger}\right] \phi(z)=0$

in which, according to (5) :

$\mathrm{n}^{2}(\mathrm{z})=\mathrm{n}_{0}{ }^{2}+\eta \mathrm{z}_{0} \Sigma_{\mathrm{m}=1}{ }^{\mathrm{M}} \delta\left(\mathrm{z}-\mathrm{mz}_{0}\right), \mathrm{Mz}_{0} \leq \mathrm{d}$

We start this analysis with the simple refractive index

$\mathrm{n}^{2}(\mathrm{z})=\mathrm{n}_{0}^{2}+\eta \mathrm{z}_{0} \delta\left(\omega \mathrm{z}-\mathrm{m \omega z} \mathrm{z}_{0}\right)$

so that the equation (A.1) becomes

$\phi^{\prime \prime}(\mathrm{z})+\omega^{2} \mathrm{n}_{0}^{2} \cos ^{2} \theta^{\dagger} \phi(\omega \mathrm{z})=-\omega^{2} \eta \mathrm{z}_{0} \delta\left(\mathrm{z}-\mathrm{mz}_{0}\right) \phi(\mathrm{z})$

We assume $\eta \ll<1$ very small and we look for the solutions of (A.4) to the $0\left(\eta^{2}\right)$ order in the

the form

$\phi(\mathrm{z})=\phi_{0}(\mathrm{z})+\eta \phi_{\mathrm{m}}(\mathrm{z})+0\left(\eta^{2}\right)$

Substituting (A.5) into (A.4) gives

$\phi_{0}{ }^{\prime}{ }^{\prime}(\mathrm{z})+\omega^{2} \mathrm{n}_{0}{ }^{2} \cos ^{2} \theta^{\dagger} \phi_{0}(\mathrm{z})+\eta\left[\phi_{\mathrm{m}}{ }^{\prime}{ }^{\prime}(\mathrm{z})+\omega^{2} \mathrm{n}_{0}{ }^{2}\right.$

$\left.\cos ^{2} \theta^{\dagger} \phi_{\mathrm{m}}(\mathrm{z})\right]=-\omega^{2} \eta \mathrm{z}_{0} \delta\left(\mathrm{z}-\mathrm{mz}_{0}\right) \phi_{0}(\mathrm{z})$

supplying the two equations

$\phi_{0}{ }^{\prime \prime}(\mathrm{z})+\omega^{2} \mathrm{n}_{0}{ }^{2} \cos ^{2} \theta^{\dagger} \phi_{0}(\mathrm{z})=0$

a)

$\phi_{\mathrm{m}}{ }^{\prime \prime}(\mathrm{z})+\omega^{2} \mathrm{n}_{0}{ }^{2} \cos ^{2} \theta^{\dagger} \phi_{\mathrm{m}}(\mathrm{z})=-\omega^{2} \mathrm{z}_{0} \delta\left(\mathrm{z}-\mathrm{mz}_{0}\right) \phi_{0}(\mathrm{z}) \mathrm{b}$

Taking as solution of (A.7a)

$\phi_{0}(\mathrm{z})=\exp \left(\mathrm{in}_{0} \cos \theta^{\dagger} \omega \mathrm{z}\right)$

the equation (A.7b) becomes

$\phi_{\mathrm{m}}{ }^{\prime \prime}(\mathrm{z})+\omega^{2} \mathrm{n}_{0}{ }^{2} \cos ^{2} \theta^{\dagger} \phi_{\mathrm{m}}(\mathrm{z})=-\omega^{2} \mathrm{z}_{0} \exp \left(\mathrm{in}_{0} \cos \theta^{\dagger} \omega \mathrm{z}\right) \delta(\mathrm{z}$ $\left.-m z_{0}\right)=-\omega^{2} z_{0} \exp \left(i n_{0} \cos \theta^{\dagger} \omega m z_{0}\right) \delta\left(z-m z_{0}\right)$

which is in fact the equation satisfied by the Green's function of the 1D-Helmholtz equation and this equation has the solution [3] for the infinite domain

$\phi_{\mathrm{m}}(\mathrm{z})=\left(\mathrm{i} \omega \mathrm{z}_{0} / 2 \pi \mathrm{n}_{0} \cos \theta^{\dagger}\right) \exp$

$\left[i \omega n_{0} \cos \theta^{\dagger}\left\{\mathrm{mz}_{0}+\left|\mathrm{z}-\mathrm{mz}_{0}\right|\right\}\right]$

Now, with the refractive index (A.2), the equation (A.1) becomes

$\phi^{\prime \prime}(\mathrm{z})+\omega^{2} \mathrm{n}_{0}^{2} \cos ^{2} \theta^{\dagger} \phi(\mathrm{z})$

$=-\omega^{2} \eta \mathrm{z}_{0} \Sigma_{\mathrm{m}=1}^{\mathrm{M}} \delta\left(\mathrm{z}-\mathrm{mz}_{0}\right) \phi(\mathrm{z})$ 
and we look for its solutions in the form

$\phi(\mathrm{z})=\phi_{0}(\mathrm{z})+\eta \Sigma_{\mathrm{m}=1}^{\mathrm{M}} \phi_{\mathrm{m}}(\mathrm{z})+0\left(\eta^{2}\right)$

Substituting (A.12) into (A.11) supplies the equations (A.7a) and (A.7b) for $\mathrm{m}=1,2 \ldots \mathrm{M}$ with the solutions (A.10) which achieves to determine (A.12) to the $0\left(\eta^{2}\right)$ order.

\section{APPENDIX B}

To obtain the amplitudes $\mathrm{R}_{\mathrm{e}}, \mathrm{T}_{\mathrm{e}}{ }^{1}, \mathrm{~T}_{\mathrm{e}}{ }^{2}, \mathrm{~A}_{\mathrm{t}, \mathrm{e}}$ for the $\mathrm{TE}$ field, we introduce the functions

$\rho_{\mathrm{e}}(\mathrm{z})=\mathrm{n}_{1} \cos \theta_{\mathrm{i}} \phi(\mathrm{z})-\mathrm{i} \phi^{\prime}(\mathrm{z}), \sigma_{\mathrm{e}}(\mathrm{z})=\mathrm{n}_{1} \cos \theta_{\mathrm{i}} \phi(\mathrm{z})+\mathrm{i} \phi^{\prime}(\mathrm{z})$ ((B.1)

Then, eliminating $\mathrm{R}_{\mathrm{e}}$ from (19) and $\mathrm{A}_{\mathrm{t}, \mathrm{e}}$ from (21) gives :

$\rho_{\mathrm{e}}(0) \mathrm{T}_{\mathrm{e}}{ }^{1}+\rho_{\mathrm{e}}(\mathrm{d}) \mathrm{T}_{\mathrm{e}}{ }^{2}=2 \mathrm{n}_{1} \cos \theta_{\mathrm{i}} \mathrm{A}_{\mathrm{e}}, \sigma_{\mathrm{e}}(\mathrm{d}) \mathrm{T}_{\mathrm{e}}{ }^{1}+\sigma_{\mathrm{e}}(0) \mathrm{T}_{\mathrm{e}}{ }^{2}$ $=0$ (B.2)

from which $\mathrm{T}_{\mathrm{e}}{ }^{1}$ and $\mathrm{T}_{\mathrm{e}}{ }^{2}$ are obtained

$\mathrm{T}_{\mathrm{e}}{ }^{1}=2 \mathrm{n}_{1} \cos \theta_{\mathrm{i}} \chi_{\mathrm{e}} \sigma_{\mathrm{e}}(0) \mathrm{A}_{\mathrm{e}}, \mathrm{T}_{\mathrm{e}}{ }^{2}=-2 \mathrm{n}_{1} \cos \theta_{\mathrm{i}} \chi_{\mathrm{e}} \sigma_{\mathrm{e}}(\mathrm{d}) \mathrm{A}_{\mathrm{e}}$ (B.3)

$\chi_{\mathrm{e}}=\left[\rho_{\mathrm{e}}(0) \sigma_{\mathrm{e}}(0)-\rho_{\mathrm{e}}(\mathrm{d}) \sigma_{\mathrm{e}}(\mathrm{d})\right]^{-1}$

so that we get at once from the first relation (21)

$\mathrm{A}_{\mathrm{t}, \mathrm{e}}=2 \mathrm{n}_{1} \cos \theta_{\mathrm{i}} \chi_{\mathrm{e}}\left[\sigma_{\mathrm{e}}(0) \phi(\mathrm{d})-\sigma_{\mathrm{e}}(\mathrm{d}) \phi(0)\right] \gamma^{-1} \mathrm{~A}_{\mathrm{e}}$

while eliminating $A_{e}$ from (19) and taking into account (B3) give

$\mathrm{R}_{\mathrm{e}}=\chi_{\mathrm{e}}\left[\sigma_{\mathrm{e}}^{2}(0)-\sigma_{\mathrm{e}}^{2}(\mathrm{~d})\right] \mathrm{A}_{\mathrm{e}}$

We proceed similarly for the TM field with the functions

$\rho_{\mathrm{m}}(\mathrm{z})=\mathrm{n}_{0}{ }^{2} \cos \theta_{\mathrm{i}} \phi(\mathrm{z})-\mathrm{i} \phi^{\prime}(\mathrm{z}), \sigma_{\mathrm{m}}(\mathrm{z})=\mathrm{n}_{0}{ }^{2} \cos \theta_{\mathrm{i}} \phi(\mathrm{z})+\mathrm{i}$ $\phi^{\prime}(\omega \mathrm{z})(\mathrm{B} .6)$

Eliminating $\mathrm{R}_{\mathrm{m}}$ from (23) and $\mathrm{A}_{\mathrm{t}, \mathrm{m}}$ from (25) gives

$\rho_{\mathrm{m}}(0) \mathrm{T}_{\mathrm{m}}{ }^{1}+\rho_{\mathrm{m}}(\mathrm{d}) \mathrm{T}_{\mathrm{m}}{ }^{2}=2 \mathrm{n}_{0} \mathrm{n}_{1} \cos \theta_{\mathrm{i}} \mathrm{A}_{\mathrm{m}}$,

$\sigma_{\mathrm{m}}(\mathrm{d}) \mathrm{T}_{\mathrm{m}}{ }^{1}+\sigma_{\mathrm{m}}(0) \mathrm{T}_{\mathrm{m}}{ }^{2}=0$

from which we get

$\mathrm{T}_{\mathrm{m}}{ }^{1}=2 \mathrm{n}_{0} \mathrm{n}_{1} \cos \theta_{\mathrm{i}} \chi_{\mathrm{m}} \sigma_{\mathrm{m}}(0) \mathrm{A}_{\mathrm{m}}$,

$\mathrm{T}_{\mathrm{m}}{ }^{2}=-2 \mathrm{n}_{0} \mathrm{n}_{1} \cos \theta_{\mathrm{i}} \chi_{\mathrm{m}} \sigma_{\mathrm{m}}(\omega \mathrm{d}) \mathrm{A}_{\mathrm{m}}$

$\chi_{\mathrm{m}}=\left[\rho_{\mathrm{m}}(0) \sigma_{\mathrm{m}}(0)-\rho_{\mathrm{m}}(\mathrm{d}) \sigma_{\mathrm{m}}(\mathrm{d})\right]^{-1}(\mathrm{~B} .8 \mathrm{a})$

and, substituting (B.8) into the first relation (25), it comes

$\mathrm{A}_{\mathrm{t}, \mathrm{m}}=2 \mathrm{n}_{0}{ }^{2} \cos \theta_{\mathrm{i}} \chi_{\mathrm{m}}\left[\sigma_{\mathrm{m}}(0) \phi(\mathrm{d})-\sigma_{\mathrm{m}}(\mathrm{d}) \phi(0)\right] \gamma^{-1} \mathrm{~A}_{\mathrm{m}}$

while eliminating A from (22) gives taking nto account (B.7)

$\mathrm{R}_{\mathrm{m}}=\chi_{\mathrm{m}}\left[\sigma_{\mathrm{m}}^{2}(0)-\sigma_{\mathrm{m}}{ }^{2}(\mathrm{~d})\right] \mathrm{A}_{\mathrm{m}}$
To achieve to determine the TE and TM fields we have just to express $\phi(0)$ and $\phi(d)$ in terms of the solutions of Appendix A.

\section{CONFLICT OF INTEREST}

None declared.

\section{ACKNOWLEDGEMENT}

None declared.

\section{REFERENCES}

[1] Born, M.; Wolf, E.; Bathia D.B. Principle of Optics. Univ. Press: Cambridge, 1999.

[2] Arzeliès, F. Optical properties of thin absorbing films. J. Opt. Soc. Am., 1957, 47, 473-482.

[3] Morse, P.M.; Feshbach, H. Methods of Theoretical Physics.Mc Graw Hill: New York, 1953

[4] Guelfand, I.M. ; Chilov, G.E. Les distributions. Dunod: Paris, 1962.

[5] VanDer, P.B.; Bremmer, H. Operational Calculus. Univ. Press: Cambridge, 1959.

[6] Joannopoulos, J.D.; Meade, R.D.; Winn, J.N. Photonic Crystals. Univ. Press: Princeton, 1995.

[7] Mitsumata, C.; Tomitu, S. Negative permeability of magnetic nano composite films for designing left-handed materials. Appl. Phys. Lett., 2007, 91, 223104-223107; doi: 10.1063/1.2816894.

[8] Buznikov, N.A.; Iabukov, I.T.; Rachmanov, A.L.; Sboyehakov, A.D. High frequency magnetic permeability of nano composite films. J. Magn. Magn. Mater., 2005, 293, 938-946.

[9] Yurasov, A.; Granowski, A.; Tarapov, S.; Clerc, J.P. High frequency magneto impedance in nano composites. J. Magn. Magn. Mater., 2006, 300, e52- e54.

[10] Qiu, J.; Gu, M. Magnetic nano composite thin films. Appl. Surf Sci., 2005, 252, 888- 892 .

[11] Mohallen, N.D.S.; Scara, L.M.; Novak, M.A.; Sinnecker, P. Magnetic nano composite prepared by sol-gel process. Braz. J. Phys., 2008, 36, 215.

[12] Ye, Q.L.; Yoshikawa, Y.; Awaga, K. Magnetic and optical properties of submicron size hollow spheres. Mater., 2010, 3, 1244-1268.

[13] Zhang, Y.; Huang, Z.; Tany, F.; Ren, J. Ferrite hollow sphere with tunable magnetic properties. Thin Solid Films, 2006, 515, 25552561.

[14] Schlachter, A.; Gruner, M.E.; Spasova, M.; Farle, M.; Entel, P. Preparation and properties of nano structured magnetic hollow nano spheres. Phase Transit., 2005, 78, 741-750.

[15] Yoshikawa, H.; Hugashida, K.; Kosuka, Y.; Horiguchi, A.; Awaya, K.; Bandow, D.; Ijma, S. Preparation and magnetic properties of hollow nano spheres of cobalt and cobalt oxide. Appl. Phys. Lett., 2004, 85, 5287-5289.

[16] Cao, S.W.; Zhu, Y.J.; Ma, M.Y.; Li, L. Hierarchically nanostructured magnetic hollow spheres of $\mathrm{FE}_{3} \mathrm{O}_{4}$ and $\mathrm{Y}^{-} \mathrm{FE}_{2} \mathrm{O}_{3}$. J. Phys. Chem., 2008, 112, 1851-1856.

[17] Caruso, F.; Sparova, M.; Sarka, A.; Giersig, M.; Caruzo, R.A. Magnetic nano composite particles and hollow spheres constructed by a sequential layering approach. Chem. Math, 2001, 13, 109-116.

(C) Pierre Hillion; Licensee Bentham Open .

This is an open access article licensed under the terms of the Creative Commons Attribution Non-Commercial License (http://creativecommons.org/licenses/by-nc/3.0/) which permits unrestricted, non-commercial use, distribution and reproduction in any medium, provided the work is properly cited. 